\title{
A Polarization Maintaining Filter based on a Liquid-Crystal-Photonic-Bandgap-Fiber
}

Scolari, Lara; Olausson, Christina Bjarnal Thulin; Turchinovich, Dmitry; Alkeskjold, Thomas Tanggaard; Bjarklev, Anders Overgaard; Eskildsen, Lars

Published in:

34th European Conference on Optical Communication

Publication date:

2008

Document Version

Publisher's PDF, also known as Version of record

Link back to DTU Orbit

Citation (APA):

Scolari, L., Olausson, C. B. T., Turchinovich, D., Alkeskjold, T. T., Bjarklev, A. O., \& Eskildsen, L. (2008). A Polarization Maintaining Filter based on a Liquid-Crystal-Photonic-Bandgap-Fiber. In 34th European Conference on Optical Communication (5 ed., pp. 1-2). IEEE.

\section{General rights}

Copyright and moral rights for the publications made accessible in the public portal are retained by the authors and/or other copyright owners and it is a condition of accessing publications that users recognise and abide by the legal requirements associated with these rights.

- Users may download and print one copy of any publication from the public portal for the purpose of private study or research.

- You may not further distribute the material or use it for any profit-making activity or commercial gain

- You may freely distribute the URL identifying the publication in the public portal 


\title{
A Polarization Maintaining Filter based on a Liquid-Crystal-Photonic- Bandgap-Fiber
}

L. Scolari (1), C. B. T. Olausson (1,2), D. Turchinovich (1), T. T. Alkeskjold (2), A. Bjarklev (1) and L. Eskildsen (1)

1: Department of Photonics Engineering, Technical University of Denmark, Ørsteds Plads 343,

DK-2800 Kgs. Lyngby, Denmark, Isc@com.dtu.dk

2: Crystal Fibre A/S, Blokken 84, 3460 Birkerød, Denmark, CBO@crystal-fibre.com

\begin{abstract}
A polarization maintaining filter based on a liquid-crystal-photonic-bandgap-fiber is demonstrated. Its polarization extinction ratio is $14 \mathrm{~dB}$ at $1550 \mathrm{~nm}$. Its tunability is $150 \mathrm{~nm}$.
\end{abstract}

\section{Introduction}

Photonic crystal fibers (PCFs) present the unique characteristic of having microholes running along their length. Liquid materials can be infiltrated into these fibers, allowing control and manipulation of their optical properties. Solid core PCFs allow light to be guided by modified total internal reflection, similarly to standard optical fibers [1]. If the microholes of these fibers are filled with a liquid having a refractive index higher than the constituent material of the fiber, antiresonances of the high-index rods give rise to discrete photonic bandgaps where the light is confined to the core [2]. In particular, among liquid materials, liquid crystals (LCs) are attractive because they exhibit very high thermo-optic and electro-optic effects, leading to the possibility of realizing tunable components [3]. All-in-fiber tunable devices such as spectral filters, switches, polarization controllers and polarimeters have been fabricated by using this technique and their tunability achieved thermally, electrically or optically $[3,4,5]$. Birefringence tunability has also been demonstrated in highly birefringent PCF filled with LCs [6]. A further degree of freedom in the design of such devices is also given by the possibility of tapering the fiber or inflating the holes, such that the bandwidth of the transmission bands can be narrowed and the shape tailored [7]. This leads to the possibility of fabricating all-in-fiber bandpass, notch, high-pass or low pass filters with a tunable operating wavelength and a tunable bandwidth, representing an alternative choice to bulk optics filters because alignment issues are overcome in this case. They are fiber compatible and may find applications in dynamic optical networks and adjusted to the specific network in order to optimize its performances.

Here a polarization maintaining (PM) filter based on a $30 \mathrm{~cm}$ PCF filled with $1.2 \mathrm{~cm}$ LC is demonstrated. A polarization extinction ratio (PER) of $14 \mathrm{~dB}$ at $1550 \mathrm{~nm}$ is measured. The PM filter is thermally tunable and a $150 \mathrm{~nm}$ shift of the bandgaps is achieved by tuning the filter from $30^{\circ} \mathrm{C}$ to $70^{\circ} \mathrm{C}$. Such a filter can be used, for example, in mode-locked fiber lasers to perform spectral shaping and intra- and extra-cavity dispersion management. A high PER of all the elements used in fiber lasers is crucial for the laser stability.

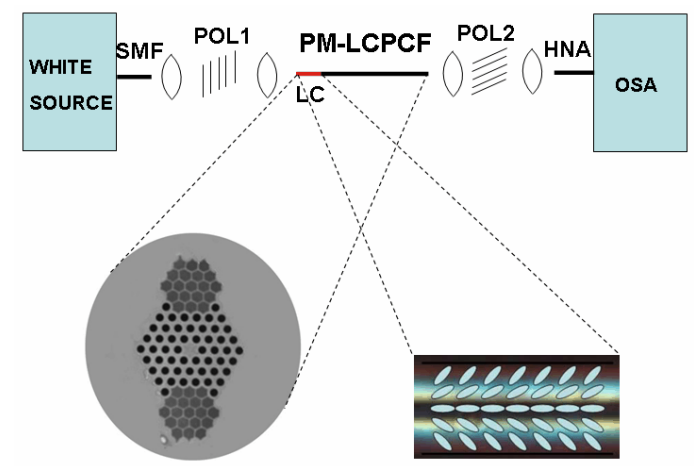

a)

b)

Figure 1 : Schematic of the setup. a) Micrograph of the fiber used in the experiment (LMA-PM-15) b)

Alignment of the $L C$ infiltrated in the fiber.

\section{Setup and discussion}

The fiber used in this experiment is a large modearea PM fiber with a core size of $15 \mu \mathrm{m}$ (LMA-PM-15) from Crystal Fibre A/S, Denmark. A cross-section of the fiber is shown in the inset a) of Fig.1. The hole size $d$ is $4.7 \mu \mathrm{m}$ and the inter-hole distance $\Lambda$ is 9.8 $\mu \mathrm{m}$. Boron rods are inserted on opposite sides of the core at the preform stage in order to obtain stressinduced birefringence that facilitates the polarization maintaining properties of the fiber. LMA-PM-15 has a birefringence $\geq 8 \times 10^{-5}$ in the range $900-1700 \mathrm{~nm}$ and a PER of $\geq 20 \mathrm{~dB}$ at $1550 \mathrm{~nm}$. A LC named MDA-003969 from Merck, Germany, is infiltrated in the PCF for $1.2 \mathrm{~cm}$ by using capillary forces. MDA-00-3969 is a dual-frequency nematic LC, with an ordinary and extraordinary index of 1.4978 and 1.7192 (measured at $589.3 \mathrm{~nm}$ ), respectively. Microscope investigations of this LC infiltrated in a $5 \mu \mathrm{m}$ silica capillary show that the alignment is splayed, with a $45^{\circ}$ angle to the boundaries, as illustrated in the inset b) of Fig.1. The LCPCF device is positioned between two polarizers. 
Lenses with a magnification of 20X and a NA of 0.5 are used to couple white light from a halogen lamp into the LCPCF, as illustrated in the setup of Fig.1. The light is collected by an optical spectrum analyzer through a high numerical aperture optical fiber.

The PER measurement is done using the crossedpolarizer method. The first polarizer is aligned along the slow or the fast axis of the fiber. The second polarizer is added and the two polarizers are iteratively rotated to minimize the transmission in the bandgaps. The resulting spectrum is measured (red curve in Fig.2). Now the second polarizer is rotated $90^{\circ}$, such that it will be co-aligned with polarizer 1. The transmission spectrum is measured again (black curve in Fig. 2). The polarization extinction ratio is the ratio between the power measured in these two cases - the polarizers in-line and the polarizers crossed - in $\mathrm{dB}$ units. In order to verify that polarizer 1 is in fact aligned along one of the two PM axes, polarizer 1 is rotated $90^{\circ}$ and the same measurements as above are repeated (green and blue curves). The transmission spectra for these two cases are expected to be the same if polarizer 1 is aligned along one of the two PM axes. In Fig. 2 it is possible to notice a small difference between them and we believe that this is caused by the fact that the LC alignment does not have a perfect cylindrical symmetry in the holes of the fiber. A PER of $14 \mathrm{~dB}$ is measured at $1550 \mathrm{~nm}$ and a PER of $17 \mathrm{~dB}$ is measured at $1200 \mathrm{~nm}$.

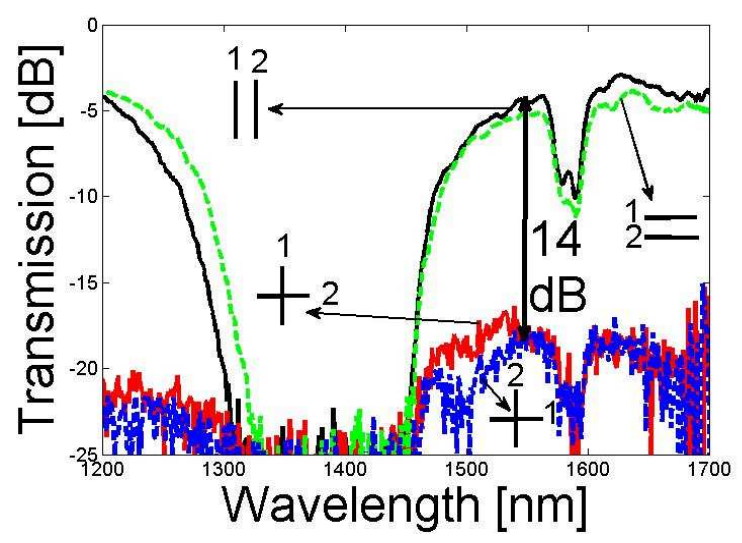

Figure 2 : Normalized transmission spectrum measured with crossed (red and blue curve) and inline polarizers (black and green).

The thermal tunability of the PM LCPCF filter is investigated by positioning the part of the fiber filled with LC on a thermal plate. A standard SMF connected to a white light source is butt-coupled to the filter and the transmission spectrum is measured using an optical spectrum analyzer. The temperature of the thermal plate is varied from $30^{\circ} \mathrm{C}$ to $70^{\circ} \mathrm{C}$ and the transmission spectrum taken every $10^{\circ} \mathrm{C}$. Fig. 3 shows the wavelength of the notch in the bandgap located between $1450-1700 \mathrm{~nm}$ as a function of temperature.

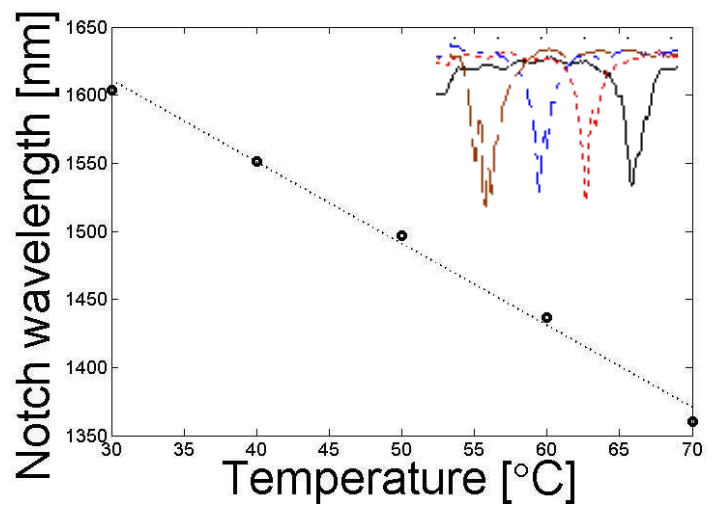

Figure 3 : Temperature tunability of the PM-LCPCF.

A tunability of $150 \mathrm{~nm}$ is achieved in this temperature range. The shift of the bandgaps as a function of temperature is almost linear. By choosing a different LC, the bandgaps can be shifted to specific wavelengths and the filter can be used for the required application. In the case of an all-PM modelocked fiber laser, the tunable PM filter can be used for spectral shaping in the cavity, ASE filtering in the amplifiers, and for tunable dispersion control both inside and outside the cavity, thus allowing for monolithic tunable pulse shaping.

\section{Conclusions}

An all-in-fiber polarization maintaining filter has been demonstrated by infiltrating a polarization maintaining PCF with LC. The PCF has two boron rods on each side of the core and maintains the polarization with a PER of $20 \mathrm{~dB}$ at $1550 \mathrm{~nm}$. By infiltrating this fiber with a LC, bandgaps are achieved in the transmission spectrum. A PER of $14 \mathrm{~dB}$ at 1550 is measured, opening up the possibility of using this device as a polarization maintaining filter, for example, in the fabrication of fiber lasers. Tunability has also been explored and a wavelength shift of $150 \mathrm{~nm}$ has been measured in the temperature range $30^{\circ} \mathrm{C}-70^{\circ} \mathrm{C}$.

\section{References}

1. P. Russell et al., Science, 299 (2003), 358-362

2. N. M. Litchinitser et al., Opt. Lett., 27 (2002), 1592-1594

3. T. T. Larsen et al., Opt. Express, 11 (2003), 25892596

4. Haakestad et al., Phot. Tech. Lett., 17 (2005), 819-821

5. T. T. Alkeskjold et al., Opt. Express, 12 (2004), 5857-5871

6. T. R. Wolinski, Opt. Quant. Electron., 39 (2007), 1021-1032

7. L. Scolari et el, Electr. Lett., 42 (2006), 1270-1271 